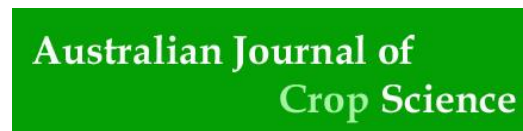

AJCS

AJCS 12(03):365-373 (2018)

ISSN:1835-2707

doi: 10.21475/ajcs.18.12.03.pne680

\title{
Influence of nitrogen fertilization on the characteristics of potato starch
}

\author{
Juliana Marques Ebúrneo, Emerson Loli Garcia, Thaís Paes Rodrigues dos Santos, Emerson de Freitas \\ Cordova de Souza, Rogério Peres Soratto, Adalton Mazetti Fernandes, Magali Leonel*
}

Center for Tropical Roots and Starches (CERAT), São Paulo State University (UNESP), Botucatu, São Paulo, Brazil

*Corresponding author: mleonel@cerat.unesp.br

\begin{abstract}
This study evaluated the effect of nitrogen fertilization rates on the characteristics of potato starch. The experimental design was randomized block with four replications. The treatments were composed of four rates of $\mathrm{N}\left(0,80,120\right.$ and $\left.160 \mathrm{~kg} \mathrm{ha}^{-1}\right)$. After 117 days of planting the harvested tubers were sanitized and the starch extracted. The starches of the different treatments were analyzed for the shape and distribution of size, X-ray pattern, crystallinity, amylose, minerals, pasting and thermal properties. Results showed that the fertilization did not cause alteration in the shape of the starch granules but the sizes of granules increased with the application of higher rates of nitrogen fertilizer. All potato starches had X-ray pattern B-type and crystallinity decreased when nitrogen fertilizer rates increased up to $120 \mathrm{~kg} \mathrm{ha}^{-1}$. Fertilization did not interfere in content of amylose. Nitrogen rates promoted a decrease in the phosphorus, calcium and magnesium contents in the starches. The starches had their initial and peak temperatures of gelatinization decreased with increasing fertilizer rates, but there was no interference of this practice in the enthalpy. The highest peaks of viscosity and breakdown were observed in starch extracted from potatoes grown with the application of $80 \mathrm{~kg} \mathrm{ha}^{-1}$ of Entec ${ }^{\circledR} 26$ fertilizer. These results indicated important modifications in potato starch properties grown at different rates of nitrogen fertilization and can provide information for starch applications in the food and non-food industries.
\end{abstract}

Keywords: Solanun tuberosum; nitrogen; starch, minerals; thermal properties.

Abbreviations: $P \_$phosphorus; $T_{0} \_$onset temperature; $T_{p} \_$peak temperature; $T_{f}$ final temperature; $\Delta T \_r a n g e$ of temperature; $\Delta H_{-}$ enthalpy change

\section{Introduction}

Potato is a tuber that is widely distributed and highly cultivated worldwide, with the largest harvest areas concentrated in Asia and Europe (FAO, 2017). In Brazil, the oleracea variant has the highest production and is cultivated not only in the Southeast and South regions but also in the Central-West and Northeast regions. The states with the highest potato production include Minas Gerais, Paraná, São Paulo, and Rio Grande do Sul.

The yield and quality of potatoes are influenced by the plant variety, environmental conditions, and cultivation practices. The potato cultivation cycle in tropical and subtropical conditions varies from 90 to 110 days depending on the cultivar. Considering its high productivity and relatively short cultivation cycle, potato consumes large amounts of nutrients that exist in a form readily available in soil.

Fertilizer application has important effects on potato quality and yield. Potatoes can absorb large quantities of nutrients from the soil during the cultivation period, especially nitrogen $(\mathrm{N})$, phosphorus $(\mathrm{P})$, and potassium (K) (Westermann, 2005; White et al., 2007; Öztürk et al., 2010). Nitrogen $(\mathrm{N})$ is the most abundant macronutrient in plants that can be absorbed in the form of ammonium $\left(\mathrm{NH}_{4}^{+}\right)$or nitrate $\left(\mathrm{NO}_{3}{ }^{-}\right)$. In potato, nitrogen availability influences the development of the aerial parts of the plant, tuber growth and differentiation, and the chemical composition of tubers (Long et al., 2004; Goffart et al.; 2008; Michalska et al., 2016).

In the past decades, various research efforts have been directed towards optimizing the efficiency of nutrient utilization by plants, with the goal of reducing production costs, preventing the destruction of environmental resources, and increasing crop yields (Zebarth et al., 2009). Approximately $40 \%$ to $60 \%$ of the total nitrogen applied using fertilizers is utilized by the potato plant, and a large percentage of the residual nitrogen is incorporated into the soil organic matter, which in turn has a high risk of being leached (Zebarth et al., 2007; Goffart et al., 2008). Nitrogen losses are more pronounced in regions with high rainfall indices, because these conditions produce plants with shallow and undeveloped root systems (Heckman, 2002).

The percentage of accumulated nitrogen in Ágata potato was determined to be $13 \%$ in the vegetative growth phase, $8 \%$ in the tuberization phase, $43 \%$ in the initial stage of tuber filling, $34 \%$ in the second half of the tuber filling stage, and $2 \%$ in the maturation stage. Therefore, the use of fertilizers 
that contain $\mathrm{NH}_{4}^{+}$and $\mathrm{NO}_{3}{ }^{-}$and additionally some types of nitrification inhibitors represent a good strategy for satisfying the high nitrogen demand by potato plants during the growth cycle (Arregui and Quemada, 2008; Fernandes et al., 2011; Migliorati et al., 2014).

Potatoes are one of the most important crops that act as food sources for the global population. Potatoes also serve as important materials for various industrial processes and for starch production (Šimková et al., 2013).

Approximately 60 million tons of starch is extracted annually worldwide from various cultures. Starches obtained from different sources are used to produce food products, pharmaceuticals, and non-edible products, such as fertilizers, seed coatings, and paper. Starch properties influence the texture of food and have various applications as thickeners, colloidal stabilizers, gelling agents, bulking agents, water retention agents, and adhesives (Hermansson and Svegmark, 1996; Singh et al., 2003).

The properties of starch depend on its physical and chemical characteristics. Starch has been demonstrated to be considerably influenced by the type of cultivar, as well as the environmental conditions and cultivation practices applied during cultivation (Šimková et al., 2013; Leonel et al., 2016).

In Brazil, potato is commercialized mainly in natura and does not undergo further processing to produce starch. However, advances in the starch industry have provided information on the characteristics of the starches as a function of the cultivars planted in the country and have contributed knowledge on the influence of cultivation conditions on the characteristics of the applicability of the produced starches (Leonel et al., 2016; Santos et al., 2016). Brazil is the largest country in South America and the fifth largest in the world, and it has the potential to expand its agricultural capacity. The GDP of the Brazilian agribusiness has continued to increase in recent years and emphasis has been placed on the agricultural sector, thereby justifying research investments that integrate with the industrial and production sectors, such as starch companies.

Thus, considering the importance of potato in the agribusiness and the hypothesis that nitrogen fertilization could affect the characteristics of starch, the present study aimed to evaluate the effect of nitrogen fertilization rates during potato cultivation on the shapes and sizes of granules, X-ray diffraction pattern, crystallinity, amylose content, and mineral contents, as well as the pasting and thermal properties of the starches.

\section{Results}

\section{Effect of nitrogen on shape and size of starch granules}

Based on microscopic analysis, the potato starches exhibited cylindrical and oval shapes and comprised mixtures of small, medium, and large granules. The observed differences in granule shapes were attributed to differences in nitrogen fertilization rates. The observed shapes of the potato starches were consistent with previous results found in the literature (Liu et al., 2007; Wang et al., 2016) (Fig.1).

Analysis of the starch granules from the different treatments showed that starch granules produced the following three main size distribution bands: granules with diameter smaller than $20 \mu \mathrm{m}$, granules with diameters ranging from 21 to $50 \mu \mathrm{m}$, and larger granules with diameters ranging from 51 to $75 \mu \mathrm{m}$. Medium-sized granules were predominant in all treatments with nitrogen fertilization. Higher amounts of nitrogen fertilizers applied during potato cultivation were associated with larger sizes of the starch granules and a decreased proportion of small granules, which indicated that the growth conditions of potato influence the important characteristics of starch (Fig.1).

\section{Effect of nitrogen on X-ray diffraction pattern and cristallinity}

Starch macromolecules are organized as amorphous and semi-crystalline granular rings. A starch molecule is formed by two macromolecules, the amylose and amylopectin. Amylose is a linear polymer with few branches (4\%-6\%), while amylopectin is the major polymer comprising starch and is highly branched with a high molecular weight. The short lateral chains of amylopectin are known to form double helices that associate into clusters. These structures are highly compact that originate from the crystalline regions and alternate with regions that are amorphous, less branched, and compact regions (Perez et al., 2009; Kozlov et al., 2007; Bello-Pérez et al., 2006).

Non-modified starches can be divided into types A, B, and $\mathrm{C}$ according to their X-ray patterns. In this study, the X-ray diffraction patterns of examined starches were not altered by the $\mathrm{N}$ levels. However, the starches obtained from potatoes cultivated with higher nitrogen levels had lower peak intensities. All samples had peaks located at 5.6, 15, 17, 18 , and $23^{\circ}$ at $2 \theta$, with the peak at $5.6^{\circ}$ having a medium intensity and the peak at $17^{\circ}$ having a strong intensity. Based on these peaks, the potato starches were classified under the B-type (Fig.2). This pattern also was observed by Zobel (1964, 1988), Jane et al. (1999), Buléon et al. (1998) and Protserov et al. (2000).

The relative crystallinity of the starches ranged from $16.59 \%$ to $22.16 \%$. Higher nitrogen fertilization rates during potato cultivation were associated with lower relative crystallinities of the starches (Fig. 2), thereby demonstrating the effects of growth conditions on the structure of the starch granules.

\section{Effect of nitrogen on amylose and minerals contents}

Amylose is a naturally occurring linear polysaccharide composed of $\alpha-1,4-D$-glucose units. The amylose content of starch is a crucial factor that influences the characteristics of starch, such as pasting properties and enzymatic susceptibility. In humans and other monogastric animals, amylose is more slowly digested than amylopectin (Stawski, 2008). In addition, amylose is anhydrous and can be used to produce films for use in various industrial applications.

In the present study, the starches had amylose contents ranging from $28.79 \%$ to $31.91 \%$. Nitrogen content was not found to influence amylose content. Phosphorus is an important component of potato starch that primarily exists as monoester phosphate (Kasemsuwan and Jane 1996). Phosphorus, when covalently bound to the starch granules, facilitates the incorporation of water molecules into the starch granules because of its ionic nature, thereby altering the functional properties of the starch, such as gelatinization 
Table 1. Characteristics of experimental area.

\begin{tabular}{lc}
\hline Characteristics & \\
\hline GPS & $23^{\circ} 02^{\prime} 27^{\prime \prime} \mathrm{S}$ \\
Above sea level $(\mathrm{m})$ & $48^{\circ} 47^{\prime} 57^{\prime \prime} \mathrm{W}$ \\
Soil classification & 744 \\
Clay Soil characteristics $(0-0,20 \mathrm{~m}$ of depth) & Oxisol clayey loam \\
$\mathrm{pH}\left(1: 2.5\right.$ soil/CaCl ${\left.\text { suspension } 0.01 ~ \mathrm{~mol} \mathrm{~L}^{-1}\right)}^{-3})$ & 5.8 \\
Organic matter $\left(\mathrm{g} \mathrm{dm}^{-3}\right)$ & 23.3 \\
$\mathrm{P}_{\text {resin-extractable }\left(\mathrm{mg} \mathrm{dm}^{-3}\right)}$ & 64.4 \\
$\mathrm{~K}\left(\mathrm{mmol}_{\mathrm{c}} \mathrm{dm}^{-3}\right)$ & 1.9 \\
Ca $\left(\mathrm{mmol}_{\mathrm{c}} \mathrm{dm}^{-3}\right)$ & 20.6 \\
$\mathrm{Mg}\left(\mathrm{mmol}_{\mathrm{c}} \mathrm{dm}^{-3}\right)$ & 5.8 \\
$\mathrm{H}+\mathrm{Al}\left(\mathrm{mmol}_{\mathrm{c}} \mathrm{dm}^{-3}\right)$ & 18.6 \\
Cation exchange capacity $\left(\mathrm{mmol}_{\mathrm{c}} \mathrm{dm}^{-3}\right)$ & 46.8 \\
Base saturation $(\%)$ & 28.2 \\
Sand $\left(\mathrm{g} \mathrm{kg}^{-1}\right)$ & 864 \\
Silt $\left(\mathrm{g} \mathrm{kg}^{-1}\right)$ & 10 \\
Clay $\left(\mathrm{g} \mathrm{kg}^{-1}\right)$ & 126 \\
\hline
\end{tabular}
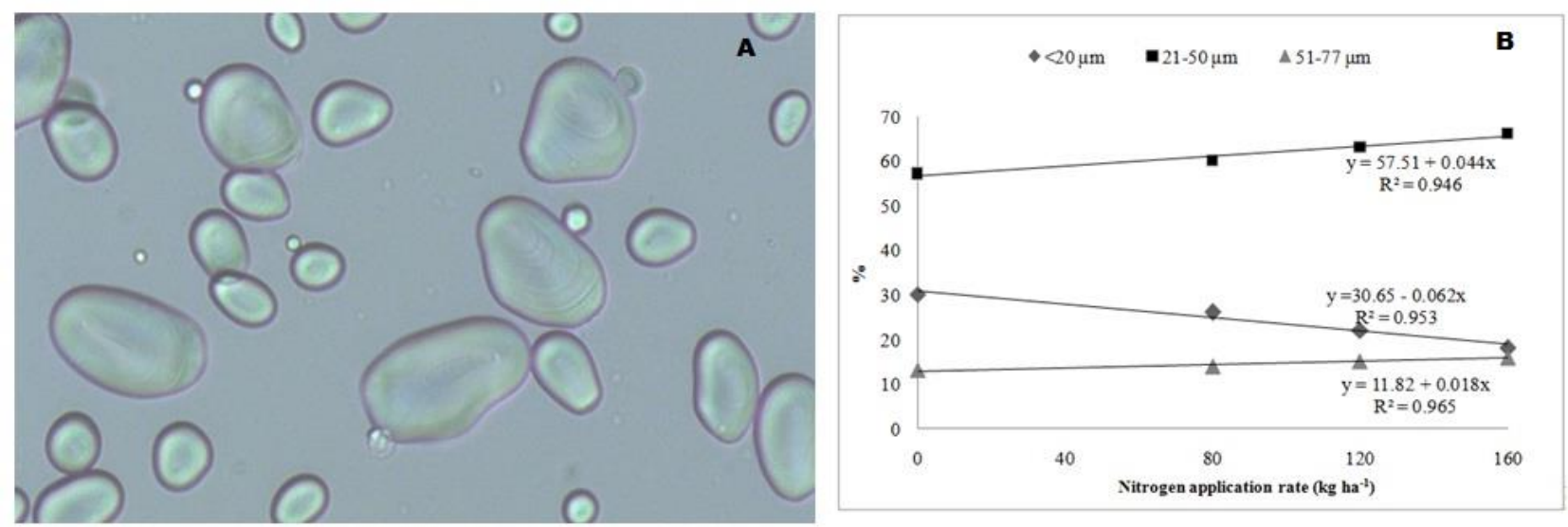

Fig 1. Shapes of potato granule starch observed in optical microscopy (40x) (A) and effect of nitrogen rates on granule size distribution of potato starch (B).
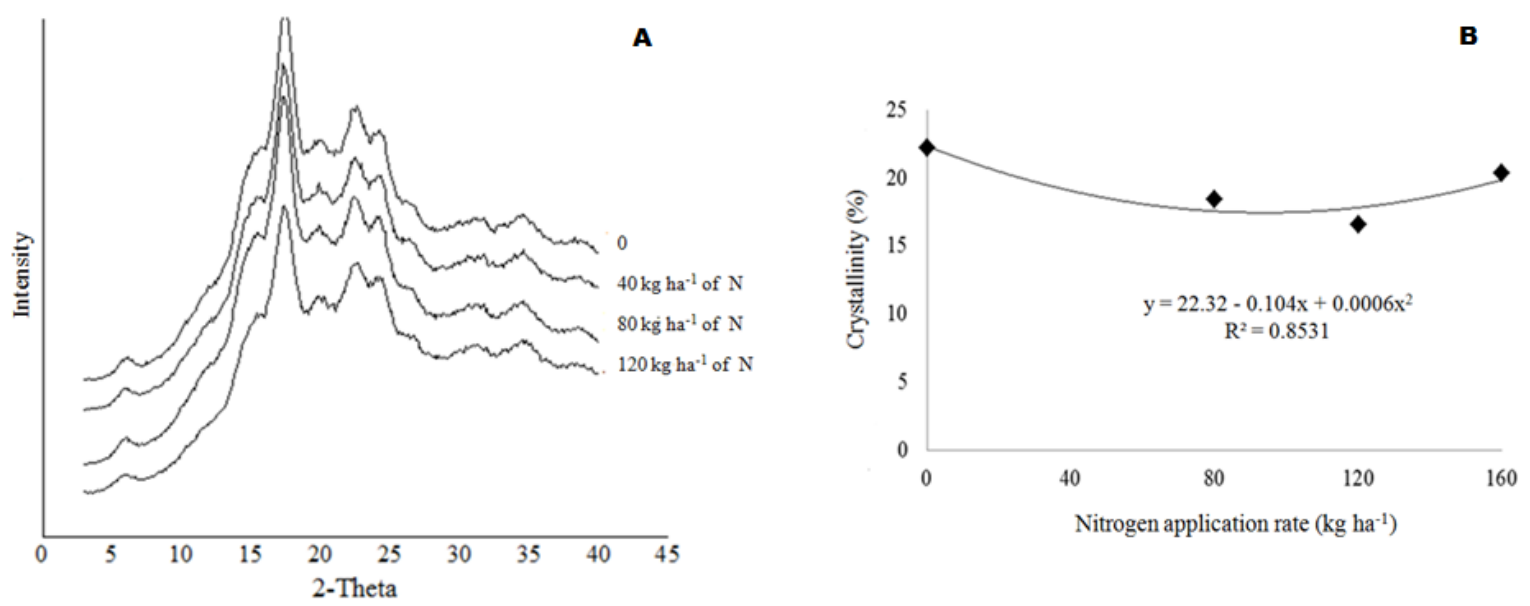

Fig 2. Effects of nitrogen rates on X-ray diffraction patterns (A) and crystallinity indexes of potato starches (B). 


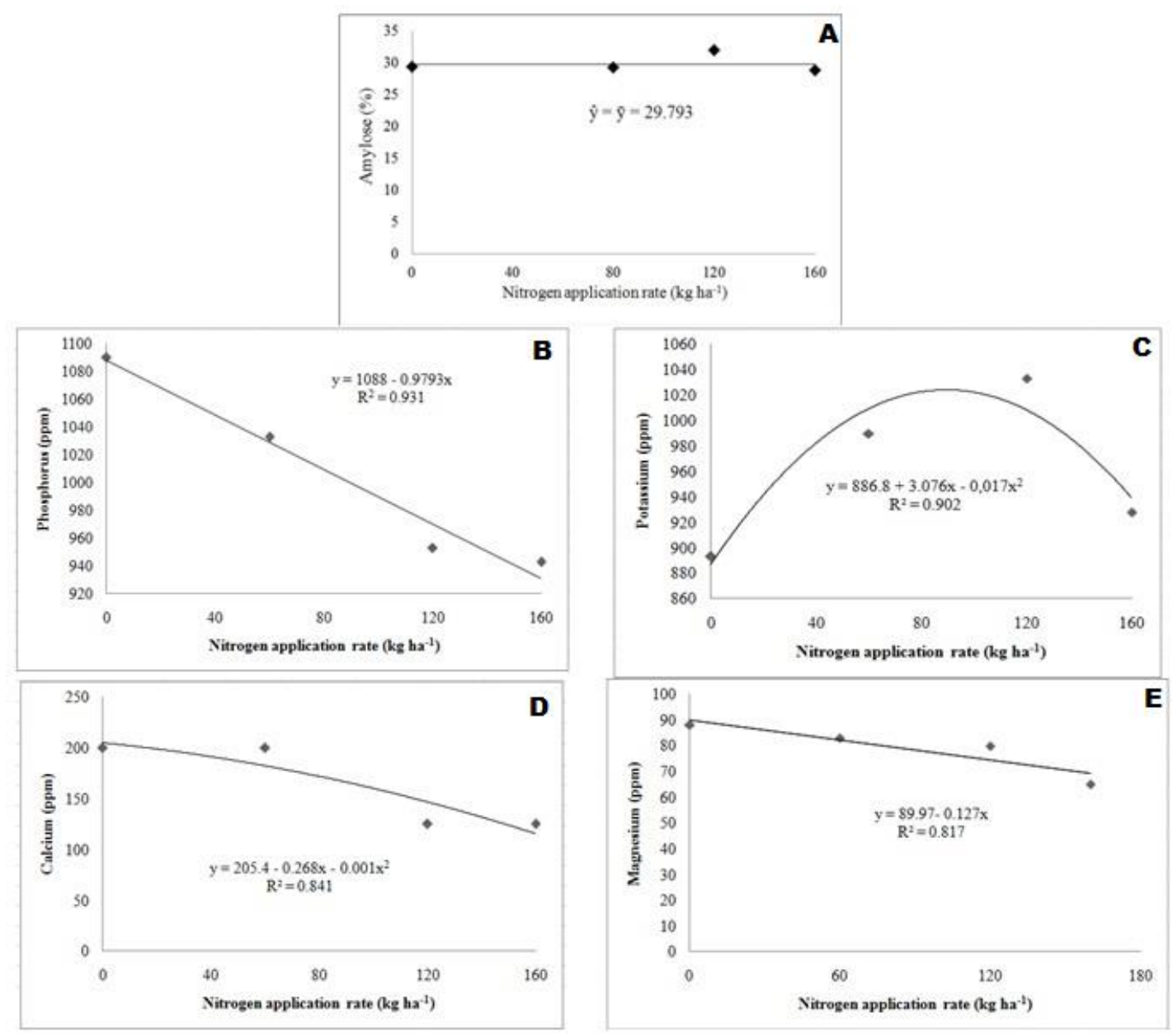

Fig 3. Effects of nitrogen rates on amylose $(A)$ and minerals $(B, C, D$ and $E)$ contents in potato starches.
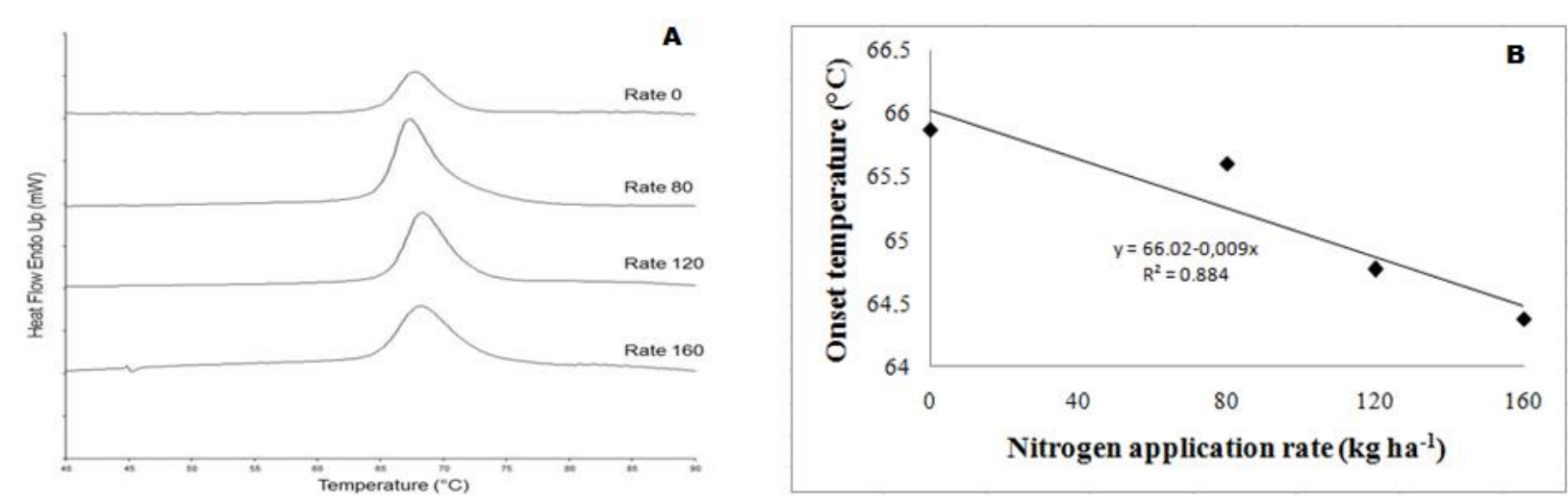

Fig 4. Effects of nitrogen rates on DSC thermograms of potato starch (A) and onset temperature (To) of starches (B). 


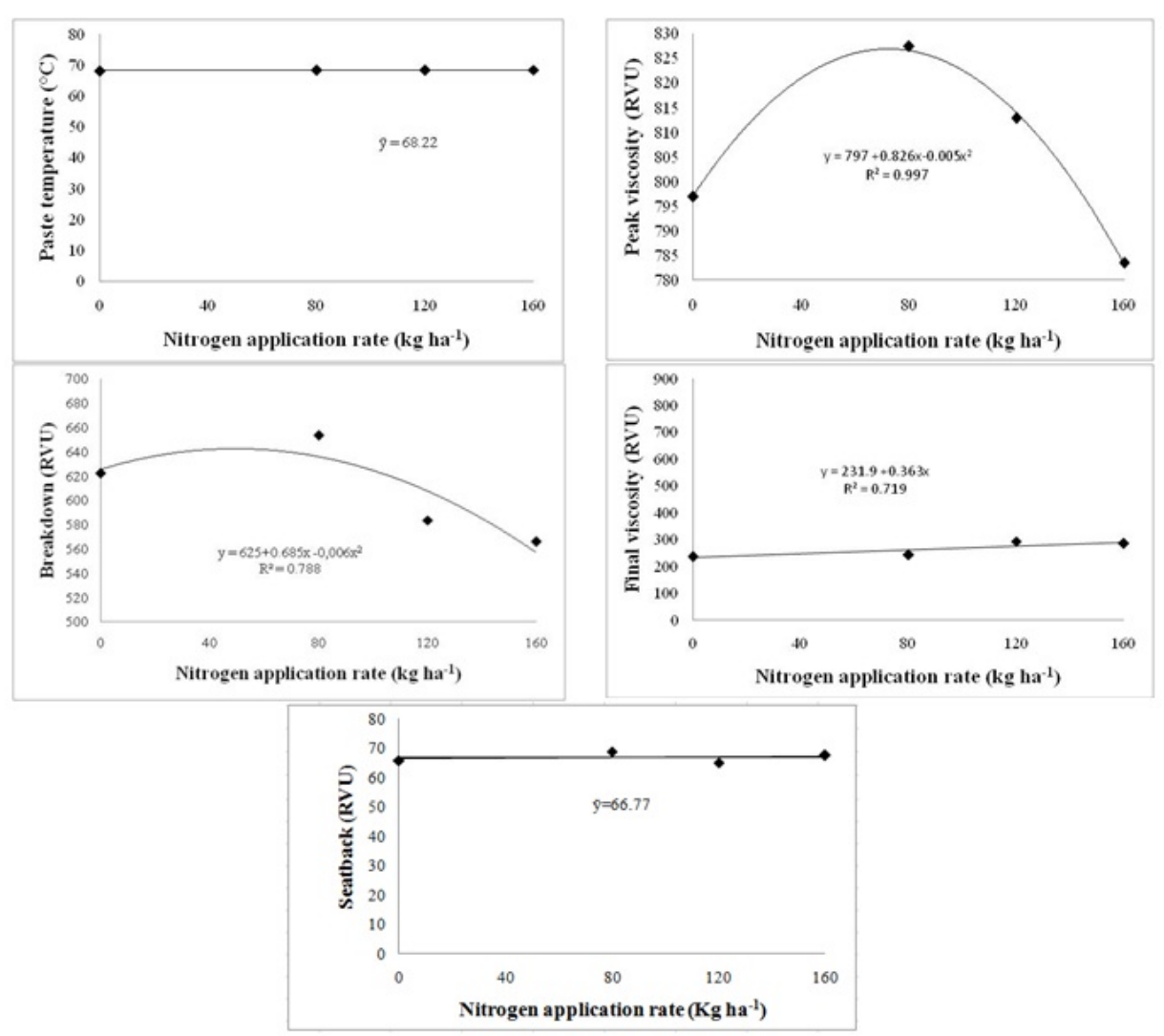

Fig 5. Pasting properties of potato starches on different nitrogen application rate. (A) Paste temperature; (B) Peak viscosity; (C) Breakdown; (D) Final viscosity; (E) Seatback.

retrogradation, and swelling power (Hoover 2001; Blennow et al., 2000; Noda et al., 2007; Leonel et al., 2016). In addition to phosphorus, potato starch also naturally contains metal cations that are attached to the phosphate ester groups through ionic interactions (Kainuma et al., 1976; Zaidul et al., 2007; Noda et al., 2014).

The phosphorus levels in the potato starches ranged from 943 to $1090 \mathrm{ppm}$. We observed a negative linear relationship between the nitrogen fertilization rates and the phosphorus contents in the starch. The phosphorus levels obtained in this study were lower than those reported by Leonel et al. (2016) and Noda et al. (1998), who reported average phosphorus contents of 576 and 774 ppm, respectively. However, our results were similar to those reported by Noda et al. (2006) (1129 ppm), demonstrating the high variability in phosphorus contents of potato starches depending on cultivation conditions and cultivars used. Analysis revealed that the potato starches had high potassium contents, with the highest values observed in the starch extracted from potatoes grown with $120 \mathrm{~kg} \cdot \mathrm{ha}^{-1}$ nitrogen (Fig.3). Noda et al. (2014) also reported high potassium contents in commercial potato starches, with the obtained phosphorus, potassium, calcium, and magnesium contents of $801,663,99$, and 89 ppm, respectively.

\section{Effect of nitrogen on thermal and pasting properties}

When heated in excess of water, starches showed a single symmetrical endothermic transition. Initial temperature $\left(T_{0}\right)$, peak temperature $\left(T_{p}\right)$, and conclusion temperature $\left(T_{c}\right)$ of all potato starches examined ranged from 64.37 to 65.87 으, 67.19 to $68.03 \stackrel{\circ}{\circ}$, and 70.79 to $71.98 \stackrel{\circ}{ }$, respectively (Fig.4). Nitrogen application rates did not influence $T_{c}$ and enthalpy for gelatinization $\left(\Delta \mathrm{H}_{\mathrm{gel}}\right) . \mathrm{T}_{\mathrm{o}}$ and $\mathrm{T}_{\mathrm{p}}$ were only slightly higher under lower nitrogen fertilization rates.

The effects of nitrogen fertilization rates on the thermal properties of starch were also reported by Zhu et al. (2017), who observed that high nitrogen levels resulted in considerably higher enthalpy $\left(\Delta \mathrm{H}_{\text {gel }}\right)$ and lower gelatinization temperature. The different gelatinization temperatures at the different $\mathrm{N}$ fertilization rates may be related to the observed differences in granule sizes, as well as crystallinity. The changes that occur in starch granules during gelatinization and retrogradation substantially influence their pasting behaviors, which were primarily determined based on changes in viscosity during heating and cooling of the starch dispersions. Analysis of the pasting properties of the potato starches showed that they have pasting temperatures ranging from 67.94 to 68.38 ㅇ, peak viscosities ranging from 794.63 to $827.46 \mathrm{RVU}$, breakdowns ranging from 565.99 to $653.28 \mathrm{RVU}$, final viscosities ranging from 236.28 to $294.25 \mathrm{RVU}$, and seatbacks ranging from 65.76 to $67.51 \mathrm{RVU}$.

Our findings demonstrated the effects of nitrogen fertilization on peak viscosity, breakdown, and final viscosity. Nitrogen fertilization was not found to influence seatback. Under high nitrogen levels, potato starches showed lower peak viscosity and breakdown and higher final viscosity (Fig.5). 


\section{Discussion}

The sizes of the starch granules may reflect their biosynthetic age. Termination of starch synthesis at different growth stages is known to cause higher variability in particle structure and properties of the starch granules (Wang et al., 2016). The effect of nitrogen rates on granule size distribution was also demonstrated in rice cultivated with varying levels of nitrogen (Zhu et al., 2017). In this study, our findings also revealed that $\mathrm{N}$ rate significantly influenced the volume distribution of rice starch granules. However, a previous study showed that higher $\mathrm{N}$ levels led to an increase in the proportion of medium and small granules.

The sizes of starch granules are major determinants of starch properties. Singh and Kaur (2004) reported that the large granules of potato starch had slightly higher amylose content and greater swelling power than those of smaller granules. In addition, small granules showed a more heterogeneous distribution of the acetyl group (Chen et al., 2004). On the other hand, Wang et al. (2016) showed that the fraction containing smaller granules exhibited spherical shapes and A-type patterns, while the fraction containing large granules exhibited ellipsoidal shapes and B-type patterns.

Results showed that all potato starches had B-type crystallinity regardless of nitrogen fertilization rate. In the Btype structure, the double helices are arranged into a hexagonal structure, and the internal part of the structure contains a cylindrical region filled with water molecules coordinated to the hydroxyl groups of the carbohydrate residues. The B-type structure is typically formed in starch granules containing amylopectin with long chains (Hizukuri 1985, Jane and Shen 1993, Jane et al., 1997). Thus, the Btype starch has the most number of branch points clustered in the amorphous region, making them more susceptible to acid hydrolysis and hydrothermal treatment (Jane et al., 1997; Jyothi et al., 2010).

The effect of nitrogen fertilization on crystallinity (Fig. 2) may be related to granule formation, which was observed based on the effects of $\mathrm{N}$ levels on granule size distribution (Fig. 1).

Our results showed that the amylose content of starch in Ágata differed from that reported by Santos et al. (2016) $(17.50 \%)$ for the same cultivar, but was very close to that reported by Leonel et al. (2015), who also analyzed starch produced from the same cultivar and grown in the same region as in the current experiment $(29.8 \%)$. The observed differences in the amylose content for the same cultivar may be because of differences in the developmental stage of the plant, as well as local growth conditions. While evaluating the characteristics of starch extracted from 16 potato cultivars grown in five localizations, Šimková et al. (2013) observed a variation in the amylose content ranging from $18.79 \%$ to $22.95 \%$, and reported that the cultivar used and the local growing conditions affect the amylose content.

Starch extracted from potatoes without nitrogen fertilization showed higher levels of phosphorus, calcium, and magnesium, demonstrating the interaction of these minerals in starch (Fig. 3). Zaidul et al. (2007) reported that calcium, magnesium, and other cations form crosslinks with phosphate ester groups of adjacent amylopectin chains driven by ionic forces and that these bonds may affect the rheological properties of the starches.

Some studies have described that higher levels of calcium and magnesium in native starches are highly desired for industrial production because increased calcium and magnesium intake may contribute to reduced risk of developing type 2 diabetes and osteoporosis (Liu et al., 2006; Villegas et al., 2009; Noda et al., 2014).

Gelatinization temperature has been known to depend on the stability of amorphous and crystalline regions of starch. Interestingly, nitrogen fertilization rates influenced the gelatinization temperatures $\left(T_{0}\right.$ and $\left.T_{p}\right)$ of the starches, suggesting that nitrogen levels influence the formation of crystalline and amorphous regions in starch. Higher gelatinization temperatures may produce more stable amorphous regions and more ordered crystalline structures in starch. However, the effects of cultivation practices on granules sizes and consequently on gelatinization temperatures should also be noted.

Analysis of pasting properties showed that nitrogen application rates influenced peak viscosity and breakdown. Peak viscosity leads to hot water swelling of the starch granules, which reflect the ability of the ordered starch to hydrate and swell. Breakdown is a measure of the stability of the product at high temperatures under mechanical agitation. Final viscosity is an important parameter in food production because it influences the viscosity of the food product.

The observed effects nitrogen fertilization during potato cultivation on these properties can be related to the minerals in the starch. In a previous study, Lu et al. (2011) reported that potato starches with high phosphorus contents tend to exhibit high peak viscosity and breakdown in their pasting profiles. Zaidul et al. (2007) also discussed the influences of calcium and magnesium on the pasting properties of starch.

\section{Materials and Methods}

\section{Experimental conditions}

Our experiments were conducted under field conditions in areas where potato is commercially produced in Avaré city, São Paulo state, Brazil. Prior to the experiments, a total of 20 subsamples were collected from the top layer of the soil at a depth of $0-20 \mathrm{~cm}$ for determination of soil chemical properties.

The preparation of the soil in the experimental area was performed using the following steps: desiccation, two heavy harrows, scarification, plowing, and third harrowing on the eve of planting. Fertilization was done using $384 \mathrm{~kg} \cdot \mathrm{ha}^{-1}$ of $\mathrm{P}_{2} \mathrm{O}_{5}$ and $100 \mathrm{~kg} \cdot \mathrm{ha}^{-1}$ of $\mathrm{K}_{2} \mathrm{O}$ in the planting grooves. After fertilization, the furrows were mechanically created and the planting was performed manually with a spacing pattern of $0.80 \mathrm{~m}$ in between rows and $0.35 \mathrm{~m}$ in between plants. Certified Ágata type III seeds, with a mean mass of $40 \mathrm{~g}$ were used. At 25 days after planting, $150 \mathrm{~kg} \cdot \mathrm{ha}^{-1}$ of $\mathrm{K}_{2} \mathrm{O}$ was applied. The experimental design was a randomized block with four replications. Nitrogen was applied at four concentrations in fertilization treatments $(0,80,120$, and $160 \mathrm{~kg} \cdot \mathrm{ha}^{-1}$ ) in the form of the Entec $^{\circledR} 26$ fertilizer. Nitrogen was applied at a dose of $80 \mathrm{~kg} \cdot \mathrm{ha}^{-1}$ in the planting grooves. 
Nitrogen rates of 120 and $160 \mathrm{~kg} \cdot \mathrm{ha}^{-1}$ were distributed with the application of $40 \mathrm{~kg} \cdot \mathrm{ha}^{-1}$ of $\mathrm{N}$ in the planting and the remaining in coverage before heaping. Irrigation and phytosanitary management of the crop were performed according to the technical recommendations. Plants were desiccated using Diquat ( $331 \mathrm{~g}$ i.a. $\mathrm{ha}^{-1}$ ) at around 100 days after planting, and starch extraction was performed at 17 days after the tubers were harvested.

\section{Starch extraction}

Samples $(4 \mathrm{~kg}$ ) of potato tubers from each treatment replicate were washed and cut into $\sim 3-\mathrm{cm}$ sections. Starches were obtained via physical extraction in cold water. Potatoes were disintegrated with water at a $1: 1(\mathrm{v} / \mathrm{v})$ ratio using a stainless steel industrial blender for $2 \mathrm{~min}$. The suspension was filtered through sieves with apertures of 60 Tyler $(0.250$ $\mathrm{mm})$ and 170 Tyler $(0.088 \mathrm{~mm})$. The bagasse remaining in the sieves was milled again in a blender under the same conditions to remove residual starch. The starch suspension recovered from the bagasse was mixed into the first suspension and placed in a cold room at $5{ }^{\circ} \mathrm{C}$ for $6 \mathrm{~h}$ for decantation of the starch. The supernatant was discarded, and the starch was washed with water until the supernatant was clear. After discarding the supernatant, the starch was dried at $38 \stackrel{\circ}{\circ}$ in an air circulation oven.

\section{Starches analysis}

Starches extracted from the potatoes harvested from the different nitrogen fertilization treatments were analyzed for shape and size distribution of granules, X-ray diffraction pattern, crystallinity, amylose content, phosphorus, potassium, calcium and magnesium contents, pasting properties, and thermal properties.

\section{Shape and size}

The shape and size distribution of the starch granules were analyzed using an Optical Microscope (Axioskop 2 Plus model, Zeiss), and captured images were analyzed using Axio Vision Rel. 4.8.2 - SP2 (Zeiss). Ten microscopy slides were prepared for each sample, and 2 to 3 drops of $50 \%(\mathrm{v} / \mathrm{v})$ glycerin solution were added on each slide and mixed with a small amount of starch using a platinum wire. A cover slip was on the suspension while taking care to avoid entrapment of air bubbles. Representative fields of the sample were selected and observed under 10 to $40 x$ magnification. A total of 100 major diameter measurements of the starch granules per microscopy slide were analyzed (Vigneau et al., 2000; Leonel, 2007).

\section{$X$-ray diffraction}

The moisture of the starch samples was equilibrated in a desiccator containing saturated solution of $\mathrm{BaCl}_{2}$ for 10 days $\left(25^{\circ} \mathrm{C}\right.$, aw $\left.=0.9\right)$. Starch samples were compacted on aluminum support and analyzed at $25 \circ \mathrm{C}$ using a wide-angle goniometer unit (RINT2000, Rigaku, Tokyo, Japan) operated with the following settings: a monochromatic filter; copper Ka radiation; $0.8 \mathrm{~kW}$, power; $100 \mathrm{~mA}$, current; $50 \mathrm{kV}$, voltage; and rotational anode. The wavelength used was
$1.542 \AA$. Analyses were conducted between $5 \circ$ and 50 을 in $2 \theta$ with the scanning speed of 1 - $\cdot \mathrm{min}^{-1}$. Intensity was expressed in peak counts per second (cps). Relative crystallinity was quantitatively estimated based on the relationship between the area under the peaks and the total area of the diffractograms following the method of Nara and Komiya (1983) using the software Origin version 7.5 (Microcal Inc., USA).

\section{Amylose}

Starch samples were defatted by dispersing in 90\% DMSO solution, and the resulting mixtures were boiled and stirred for $1 \mathrm{~h}$ (Franco et al., 2002). lodine affinities of defatted whole starches were determined according to the methods described by Kasemsuwan et al. (1995) using a potentiometric autotitrator (716SM Titrino, Brinkmann Instrument, Westbury, NY). Amylose contents were calculated by dividing the iodine affinity of starch by $20.0 \%$ (Takeda and Hizukuri, 1987).

The minerals phosphorus, potassium, calcium, and magnesium were analyzed as previously described by Malavolta et al. (1997). Extracts were prepared and subjected to determination of the mineral contents. Samples $(500 \mathrm{mg}$ ) were weighed and placed in a digestion tube, followed by the addition of $6 \mathrm{ml}$ of $\mathrm{HNO}_{3}$ and $\mathrm{HClO}_{4}(2: 1 \mathrm{v} / \mathrm{v})$. The nitric-perchloric digestion was conducted in a digestor block by gradually increasing the temperature to $160 \stackrel{\circ}{ } \mathrm{C}$ and incubating at this final temperature for $40 \mathrm{~min}$. Subsequently, the temperature was raised to $210^{\circ} \mathrm{C}$ for 20 min until the extract became colorless. The extract was then transferred to a $50-\mathrm{ml}$ volumetric flask, and the volume was adjusted with deionized water.

Phosphorus was detected based on the formation of a yellow complex of the vanadomolybdophosphoric system in acidic medium. To obtain the primary reactant, $5 \%$ ammonium molybdate $\left.\left[\left(\mathrm{NH}_{4}\right)_{6} \mathrm{Mo}_{7} \mathrm{O}_{24}\right)\right]$ solution and $0.25 \%$ ammonium metavanadate $\left(\mathrm{NH}_{4} \mathrm{VO}_{3}\right)$ solution were prepared, mixed in equal parts, and stored in a refrigerator. For determination of the phosphorus content in the samples, $1.0 \mathrm{ml}$ of nitric-perchloric extract was dispensed to a spectrophotometer tube. Subsequently, $4 \mathrm{ml}$ of deionized water and $2 \mathrm{ml}$ of the primary reactant were added, and the sample was homogenized. The sample was allowed to stand for $5 \mathrm{~min}$, and the absorbance value was detected at $\lambda=420$ $\mathrm{nm}$. Phosphorus levels were calculated based on the standard curve. Samples were analyzed in triplicate.

Standard solutions were prepared, and potassium, calcium, and magnesium levels were measured using an atomic absorption spectrophotometer (Analyst 800, Perkin Elmer-USA) based on the displacement of electrons to higher energy levels. Samples were analyzed in triplicate.

\section{Pasting properties}

The pasting properties of the starches were analyzed using a Rapid Visco Analyzer (RVA), series 4 (Newport Scientific) equipped with Thermocline software for Windows. Starch samples $(2.5 \mathrm{~g})$ were dispersed in $25 \mathrm{ml}$ of distilled water, and moisture levels were adjusted to $14 \%$. The following temperature profile was used for the analysis: $50 \stackrel{\circ}{\circ}$ for 1 $\min ; 50 \stackrel{\circ}{ } \mathrm{C}$ to $95 \stackrel{\circ}{\circ}$ at a rate of $6 \stackrel{\circ}{\circ} \cdot \mathrm{min}^{-1} ; 95^{\circ} \mathrm{C}$ for $5 \mathrm{~min}$; 
and cooling down to $50 \stackrel{\circ}{\circ}$, at a rate of $6 \stackrel{\circ}{\circ} \cdot \mathrm{min}^{-1}$. Based on the resulting graph, we evaluated the pasting temperature, peak viscosity, breakdown, final viscosity and tendency to retrogradation (seatback). Analysis was performed in triplicate.

\section{Thermal properties}

Potato starch samples were weighed using aluminum pans (approximately $2.5 \mathrm{mg}$, dry basis) and mixed with distilled water $(7.5 \mu \mathrm{L})$. Pans were sealed and equilibrated for $2-4 \mathrm{~h}$ at 25을 heating in the DSC. Measurements were carried out at a heating rate of $10 \stackrel{\circ}{ } \mathrm{C} \cdot \mathrm{min}^{-1}$ from 25 to 100 oC. The instrument was calibrated using an empty pan as reference. After running the DSC program, samples were refrigerated at $4{ }^{\circ} \mathrm{C}$ for 14 days and analyzed again under the same conditions to determine the thermal properties of retrograded starches. Gelatinization temperature (onset, peak, and conclusion) and enthalpy changes of starches were determined using the Pyris 1 software from Perkin Elmer, USA. Data were reported as the means of triplicate measurements.

\section{Statistical analysis}

The data were subjected to analysis of variance. The effects of $\mathrm{N}$ fertilization rates were evaluated by conducting regression analysis. Regression coefficients were considered significant at the $5 \%$ probability level.

\section{Conclusion}

Our findings demonstrated that the cultivation practices adopted by rural producers of potato significantly influence the characteristics of starch, the main carbohydrate component of potato. Nitrogen fertilization rates were found to induce significant changes in the characteristics of the starch in Ágata. The use of nitrogen fertilizer caused an increase in the size of starch granules, decrease in mineral contents $(\mathrm{P}, \mathrm{Ca}$, and $\mathrm{Mg})$, and changes in pasting and thermal properties, including a decrease in the initial gelatinization temperature and peak viscosity, increase in the resistance against heat and agitation, and increase in the final viscosity.

\section{Acknowledgement}

The authors are grateful for the support of CNPq (Process 303373/2014-8).

\section{References}

Arregui LM, Quemada M (2008) Strategies to improve nitrogen use efficiency in winter cereal crops under rainfed conditions. Agron J. 100: 277-284.

Bello-Pérez LA, Monteal MGM, Acevedo E (2006) Almidón: definición, estrutura y propriedades. In: Lajolo FM, Menezes EW Carbohidratos em alimentos regionales iberoamericano. 7-46.
Blennow A, Bay-Smidt AM, Olsen CA, Møllera BL (2000) The distribution of covalently bound phosphate in the starch granule in relation to starch crystallinity. Int J Biol Macromol. 27:211-218.

Buléon AP, Colonna V, Planchot S, Ball S (1998) Starch granules: structure and biosynthesis. Int J Biol Macromol. 23:85-112.

Chen Z, Schols HA, Voragen AG (2004) Differently sized granules from acetylated potato and sweet potato starches differ in the acetyl substitution pattern of their amylose populations. Carbohydr Polym. 56:219-226.

FAO - Food and Agriculture Organization of the United nations. 2016. FAOSTAT: Crops. Available in: http://faostat3.fao.org/browse/Q/QC/E >, accessed in 2017 January.

Fernandes AM, Soratto RP, Silva BL (2011) Nutrient extraction and exportation by potato cultivars: I - macronutrients. SBCS. 35:2039-2056.

Franco CML, Cabral AFR, Tavares DQ (2002) Structural and physicochemical characteristics of linnerized native and sour cassava starches. Starch-Starke. 54: 469-475.

Goffart JP, Olivier M, Frankinet M (2008) Potato crop nitrogen status assessment to improve $n$ fertilization management and efficiency: Past-Present-Future. Potato Res. 51:355-383.

Hechman JR (2002) In-season soil nitrate testing as a guide to nitrogen management for annual crops. HortTechnology. 12:706-710.

Hermansson A, Svegmark K (1996) Developments in the understanding of starch functionality. Trends Food Sci Tech. 7:345-353.

Hizukuri S (1985) Relationship between the distribution of the chain length of amylopectin and the crystalline structure of starch granules. Carbohydr Res. 141:295-306.

Hoover R (2001). Composition, molecular structure and physicochemical properties of tuber and root starches: a review. Carbohydr Polym. 45:253-267.

Jane JL, Shen JJ (1993) Internal structure of the potato starch granule revealed by chemical gelatinization. Carbohydr Res. 247:279-290.

Jane JL, Wong KS, McPherson AE (1997) Branch-structure difference in starches of $A$ - and B-type $X$-ray patterns revealed by their Naegeli dextrins. Carbohydr Res. 300: 219-227.

Jane JL, Chen YY, Lee LF, McPherson AE, Wong KS, Radosavljevic $M$, Kasemsuwan T (1999) Effects of amylopectin branch chain length and amylose content on the gelatinization and pasting properties of starch. Cereal Chem. 76:629-637.

Jyothi AN, Sajeev MS, Sreekumar JN (2010) Hydrothermal modifications of tropical tuber starches. 1. effect of heatmoisture treatment on the physicochemical, rheological and gelatinization characteristics. Starch-Starke. 62:28-40.

Kainuma K, Miyamoto S, Yoshioka S, Suzuki S (1976) Studies on structure and physico-chemical properties of starch: Part 3. changes in physical properties of high phosphate potato starch by substitution of cations. J Jap Soc Starch Sci. 23: 5966.

Kasemsuwan T, Jane JL (1996) Quantitative method for survey starch phosphate derivates and starch phosfolipds by $31 \mathrm{P}$ nuclear magnetic resonance spectroscopy. Cereal Chem. 73:702-707.

Kozlov SS, Blennow A, Krivandin AV, Yuryev VP (2007) Structural and thermodynamic properties of starches extracted from GBSS and GWD suppressed potato lines. Int J Biol Macromol. 40: 449-460.

Leonel M (2007) Analysis of the shape and size of starch grains from different botanical species. Ciênc Tecnol Aliment. 27: 579-588. 
Leonel M, Carmo EL, Fernandes AM, Franco CML, Soratto RP (2016) Physico-chemical properties of starches isolated from potato cultivars grown in soils with different phosphorus availability. J Sci Food Agric. 96: 1900-1905.

Liu S, Choi HK, Ford E, Song Y, Klevak A, Buring JE, Manson JE (2006) A prospective study of dairy intake and the risk of type 2 diabetes in woman. Diabetes Care. 29:1579-1584.

Liu Q, Tarn R, Lynch D, Skjodt NM (2007) Physicochemical properties of dry matter and starch from potatoes grown in Canada. Food Chem. 105: 897-907.

Long CM, Snapp SS, Douches DS, Chase RW (2004) Tuber yield, storability and quality of Michigan cultivars in response to nitrogen management and seedpiece spancing. AJPR. 81:347357.

Lu Z-H, Yada RY, Liu Q, Bizimungu B, Murphy A, De Koeyer D, Li $X-Q$, Pinhero R G (2011) Correlation of physicochemical and nutritional properties of dry matter and starch in potatoes grown in different locations. Food Chem. 126:1246-1253.

Malavolta E, Vitti GC, Oliveira AS (1997) Avaliação do estado nutricional das plantas: princípios e aplicações. 2 edh. 319p.

Michalska A, Wojdyło A, Bogucka B (2016) The influence of nitrogen and potassium fertilization on the content of polyphenolic compounds and antioxidant capacity of coloured potato. J Food Compos Anal. 47:69-75.

Migliorati MDA, Scheera C, Gracea PR, Rowlingsa DW, Bell M, McGreeca J (2014) Influence of different nitrogen rates and DMPP nitrification inhibitor on annual $\mathrm{N}_{2} \mathrm{O}$ emissions from a subtropical wheat-maize cropping system. Agr Ecosyst Environ. 136:33-43.

Nara S, Komiya T (1983) Studies on the relationship between water-satured state and crystallinity by the diffraction method for moistened potato starch. Starch-Starke. 35:407-410.

Noda T, Takahata Y, Sato T, Suda I, Morishita T, Ishiguro K, Yamakawa O (1998) Relationship between chain length distribution of amylopectin an gelatinization properties within the same botanical origin for sweet potato and buckwheat. Carbohydr Polym. 37:153-158.

Noda T, Tsuda S, Mori M, Takigawa S, Matsuura-Endo C, Kim SJ, Hashimoto N, Yamauchi H (2006) Determination of the phosphorus content in potato starch using an energydispersive X-ray fluorescence method. Food Chem. 95: 632637.

Noda T, Kottearachchi N S, Tsuda S, Mori M, Takigawa S, Matsuura-Endo C, Kim S- J, Hashimoto N, Yamauchi H (2007) Starch phosphorus content in potato (Solanum tuberosum L.) cultivars and its effect on other starch properties. Carbohydr Polym. 68:793-796.

Noda T, Takigawa S, Matsuura-Endo C, Ishiguro K, Nagasawa K, Jinno M (2014) Preparation of calcium and magnesium fortified potato starches with altered pasting properties. Molecules. 19:14556-14566.

Öztürk E, Kavurmaci Z, Kara K, Polat, T (2010) The effects of different nitrogen and phosphorus rates on some quality traits of potato. Potato Res. 53:309-312.

Perez S, Baldwin P M, Gallant D J (2009) Structural features of starch granules I. In: Bemiller J, Whistler R. Starch: chemistry and technology. Burlington: Academic Press.149-192.
Protserov VA, Karpov VG, Kozhevnikov GO, Wasserman LA Yuryev VP (2000) Changes of thermodynamic and structural properties of potato starches (Udacha and Acrosil varieties) during biosynthesis. Starch-Starke. 52:461-466.

Santos TPR, Leonel M, Garcia EL, Carmo EL, Franco CML (2016) Crystallinity, thermal and pasting properties of starches from different potato cultivars grown in Brazil. Int J Biol Macromol. 82:144-149.

Šimková D, Lachman J, Hamouz K, Vokal B (2013) Effect of cultivar, location and year on total starch, amylose, phosphorus content and starch grain size of high starch potato cultivars for food and industrial processing. Food Chem. 141:3872-3880.

Singh N, Singh J, Kaur L, Sodhi NS, Gill BS (2003) Morphological, thermal and reological properties of starches from different botanical sources. Food Chem. 81: 219-231.

Singh N, Kaur L (2004) Morphological, thermal, rheological and retrogradation properties of potato starch fractions varying in granule size. J Sci Food Agric. 84: 1241-1252.

Stawski D (2008) New determination method of amylose content in potato starch. Food Chem. 110:777-781.

Takeda Y, Hizukuri S (1987) Structures of branched molecules of amylose of various origins, and molar fraction of branched and unbranched molecules. Carbohydr Res. 165 (1): 139-145.

Vigneau E, Loisel C, Devaux MF, Cantoni P (2000) Number of particles for the determination of size distribution from microscopic images. Powder Technol. 107:243-250.

Villegas R, Gao YT, Dai Q, Yang G, Cai H, Li H, Zheng W, Shu XO (2009) Dietary calcium and magnesium intakes and risk of type 2 diabetes: The Shanghai woman's health study. Am J Clin Nutr. 89:1-9.

Wang C, Tang C-H, Fu X, Huang Q, Zhang B (2016) Granular size of potato starch affects structural properties, octenylsuccinic anhydride modification and flowability. Food Chem. 212:453459.

Westermann DT (2005) Nutritional requirements of potatoes. AJPR. 82:301-307.

White PJ, Wheatley RE, Hammond JP, Zhang K (2007) Minerals, soils and roots. In: Vreugdenhil D (ed) Potato biology and biotechnology, advances and perspectives. Elsevier, Amsterdam, 739-752.

Zaidul ISM, Norulaini N, Omar AKM, Yamauchi H, Noda T (2007) Correlations of the composition, minerals, and RVA pasting properties of various potato starches. Starch-Starke. 59: 269276.

Zebarth BJ; Rosen CJ (2007) Research perspective on nitrogen BMP development for potato. AJPR. 84:3-18.

Zebarth BJ, Drury CF, Tremblay N, Camborius AN (2009) Opportunities for improved fertilizer nitrogen management in production of arable crops in eastern Canada: A review. Can J Soil Sci. 89:113-132.

Zhu D, Zhang H, Guo B, Xu K, Dai Q, Wei C, Zhou G, Huo Z (2017) Effects of nitrogen level on structure and physicochemical properties of rice starch. Food Hydrocolloid. 63:525-532.

Zobel HF (1964) X-ray analysis of starch granules. In R. L. Whistler (Ed.), Methods in carbohydrate chemistry, Academic Press. NewYork. 109-113.

Zobel HF (1988) Starch crystal transformation and their industrial importance. Starch-Starke. 40:1-5. 